\title{
TLR2 polymorphism (rs650082970) is associated with somatic cell count in goat milk
}

\author{
Jernej Ogorevc ${ }^{1}$, Mojca Simčič ${ }^{1}$, Minja Zorc $^{1}$, Monika Škrjanc $^{2}$, Peter Dovč ${ }^{\text {Corresp. } 1}$ \\ 1 Biotechnical Faculty, Department of Animal Science, University of Ljubljana, Ljubljana, Slovenia \\ ${ }^{2}$ Faculty of Chemistry and Chemical Technology, University of Ljubljana, Ljubljana, Slovenia \\ Corresponding Author: Peter Dovč \\ Email address: peter.dovc@bf.uni-lj.si
}

Pathogens invading the mammary gland are recognized through a range of pattern recognition receptors (PRRs), residing on the plasma membrane of mammary epithelial cells. Toll-like receptor 2 (TLR2) signalling is responsible for recognition of Gram-positive bacteria, which are the most common mastitis-causing pathogens in goats. Somatic cell counts (SCC) in milk are routinely determined in goat dairy flocks and serve as an indicator of milk quality, which is highly correlated to intramammary infections. Recently, a single nucleotide polymorphism of the TLR2 was suggested to be associated with SCC in goat milk. To further test the suggested association we genotyped 61 Slovenian Alpine goats included in the dataset. The effect of the genotype was analysed using the general linear model (GLM) procedure of SAS/STAT software. We found the TLR2 genotypes significantly ( $p=0.0007$ ) associated with milk SCC. Animals with the $A / G$ genotype had significantly ( $p$ $\leq 0.05$ ) lower SCC value in milk compared to the $G / G$ genotype. Our data suggest that the $A$ allele is the minor one and is associated with lower milk SCC scores. In the current study, we provide a validated PCR-RFLP based genotyping assay for the TLR2 SNP (rs650082970) and confirm its association with milk SCC score on a sample of Slovenian Alpine goats. Further studies to confirm the association on a larger number of animals of different breeds and to explain functional consequences of the polymorphism in relation to SCC are encouraged. 
1 TLR2 polymorphism (rs650082970) is associated with

2 somatic cell count in goat milk

3

4

5 Jernej Ogorevc ${ }^{1}$, Mojca Simčič ${ }^{1}$, Minja Zorc ${ }^{1}$, Monika Škrjanc ${ }^{2}$, Peter Dovč ${ }^{*}$

6

7 'University of Ljubljana, Biotechnical Faculty, Department of Animal Science, Ljubljana,

8 Slovenia

${ }^{2}$ University of Ljubljana, Faculty of Chemistry and Chemical Technology, Ljubljana, Slovenia

*Corresponding Author:

Peter Dovč ${ }^{1}$

Groblje 3, 1230 Domžale, Slovenia

Email address: peter.dovc@bf.uni-lj.si

\section{Abstract}

Pathogens invading the mammary gland are recognized through a range of pattern recognition receptors (PRRs), residing on the plasma membrane of mammary epithelial cells. Toll-like receptor 2 (TLR2) signalling is responsible for recognition of Gram-positive bacteria, which are the most common mastitis-causing pathogens in goats. Somatic cell counts (SCC) in milk are routinely determined in goat dairy flocks and serve as an indicator of milk quality, which is highly correlated to intramammary infections. Recently, a single nucleotide polymorphism of the TLR2 was suggested to be associated with SCC in goat milk. To further test the suggested association we genotyped 61 Slovenian Alpine goats included in the dataset. The effect of the genotype was analysed using the general linear model (GLM) procedure of SAS/STAT software. We found the TLR2 genotypes significantly $(\mathrm{p}=0.0007)$ associated with milk SCC. Animals with the $A / G$ genotype had significantly $(\mathrm{p} \leq 0.05)$ lower SCC value in milk compared to the $G / G$ genotype. Our data suggest that the $A$ allele is the minor one and is associated with lower milk SCC scores. In the current study, we provide a validated PCR-RFLP based genotyping assay for the TLR2 SNP (rs650082970) and confirm its association with milk SCC score on a 
31 sample of Slovenian Alpine goats. Further studies to confirm the association on a larger number 32 of animals of different breeds and to explain functional consequences of the polymorphism in 33 relation to SCC are encouraged.

34

35 Introduction

36

37

Mastitis, an inflammation of mammary tissue, is the major concern in the dairy sector, causing economic loses, animal welfare concerns, and reduced quality of milk and milk products. Mammary epithelial cells are the first barrier against invading pathogens and play a key role in recognition of pathogens and in induction of innate immune response during intramammary infection (Stelwagen et al., 2009). The recognition of pathogens by the innate immune system is mediated through pattern recognition receptors (PRRs), which recognise evolutionarily conserved pathogen-associated molecular patterns (PAMPs), present on the surface of pathogens (Mogensen, 2009). Toll-like receptors (TLRs) were the first recognized PRRs and are the most well-characterized (Kawai and Akira, 2011). A wide range of PRRs, including TLRs, is expressed on plasma membranes of mammary epithelial cells (Ezzat Alnakip et al., 2014). TLR2 is important for recognition of Gram-positive bacteria (Schroder et al., 2003), which are the most common mastitis-causing pathogens in goats (Bergonier et al., 2003) and TLR2 is therefore one of the crucial PRRs responsible for mammary gland immunity in small ruminants.

Somatic cell count (SCC) is a widely used indicator of milk quality and overall udder health status in dairy herds. Mammary infections correlate well with elevated levels of somatic cells in milk in cattle. This relation is a bit less straightforward in goats where somatic cell counts (SCC) are generally much higher (Paape et al., 2007) due to apocrine mechanism of milk excretion in goats, resulting in cytoplasmic particles present in milk, which could be mistakenly counted as somatic cells (Paape and Capuco, 1997). However, with proper optimization of the detection methods and use of goat specific SCC standards, SCCs serve also as an indicator of mammary health status in goats and are routinely determined in milk from dairy goat flocks (Wilson et al., 1995; Raynal-Ljutovac et al., 2007). Interestingly, no generally accepted grading criteria or legal standards exist for classification of goat milk according to SCC as are established for cow's milk. Some authors (Silanikove et al., 2014) suggest that grade A goat milk should contain up to 
61840,000 somatic cells $/ \mathrm{ml}$, and that goat milk with more than 3,500,000 cells $/ \mathrm{ml}$ should not be 62 accepted for marketing (Leitner et al., 2008).

63

64 It has been shown in cattle that expression of TLR2 is induced during intramammary infections 65 (Goldammer et al., 2004; Mitterhuemer et al., 2010; Gunther et al., 2011). In addition,

66

67

68

69

70

71

72

73

74

75

76

77

78

79

80

81

82

83

84

85

86

87

88

89

90

polymorphisms of TLR2 have been associated with milk SCC (Bai et al., 2012). A single

nucleotide polymorphism (SNP) rs650082970 was recently proposed to be associated with goat milk SCC, by sequencing the TLR2 target region of 39 goats of different breeds included in the dataset (Ruiz-Rodriguez et al., 2017). To further test the suggested association in goats, we designed a PCR-RFLP based genotyping assay and genotyped 61 does of Slovenian Alpine goat breed from a single dairy farm. Statistical analysis was conducted to determine whether the TLR2 genotypes are associated with SCC in goat milk.

\section{Materials \& Methods}

\section{Animals, phenotypic data and DNA extraction}

Hair samples from 61 does from Slovenian Alpine goat breed were obtained from animals included in the AT4 milk recording system according to the latest ICAR (https://www.icar.org/) guidelines (subsequent test days take place at 28 to 34 day intervals). A total of 863 AT4 milk records were extracted from the Central Database for Small Ruminants, maintained by the Department of Animal Science (Biotechnical Faculty, University of Ljubljana). Phenotypic data include age, parity, consecutive milk recording, milk composition (fat, protein, lactose, urea) and somatic cell count (somatic cell number per $\mathrm{ml}$ ) for the period from July 2015 to November 2017. There were seven milk recordings for each doe yearly in 2017 and 2016 and four in 2015. Does were in their first to fourth parity. Genomic DNA was extracted from hair follicles using Isolate II Genomic DNA Kit (Bioline, UK) according to the manufacturer's instructions. The collection of animal samples was carried out in accordance with the recommendations of the European Union Directive 2010/63 and the national animal testing legislation.

\section{PCR-RFLP analysis and sequencing}


91 Polymerase chain reaction (PCR) was performed to screen for the SNP rs650082970 in the PCR 92 amplified 442 bp fragment of the TLR2 gene, using forward: 5'-

93 ATCTGCGGACCCTGAAAGTA-3' and reverse: 5'-GCTGTAAAATCGCCAATTCC-3'

94 primer pair. The PCR primers were designed in Primer3 primer design tool

95 (http://bioinfo.ut.ee/primer3-0.4.0/), using goat TLR2 source sequence JQ911706 (GeneBank).

96 The amplification reactions were performed as follows: $5 \mathrm{~min}$ at $95^{\circ} \mathrm{C}, 35$ cycles at $95{ }^{\circ} \mathrm{C}$ for 30

$97 \mathrm{~s}, 58^{\circ} \mathrm{C}$ for $30 \mathrm{~s}$, and $72{ }^{\circ} \mathrm{C}$ for $30 \mathrm{~s}$, followed by final elongation step at $72{ }^{\circ} \mathrm{C}$ for 3 minutes.

98 The reaction volume was $20 \mu \mathrm{l}$ and contained $1 \mathrm{x}$ PCR buffer, $0.75 \mu \mathrm{M}$ primers, $150 \mu \mathrm{M}$ dNTPs,

$991.2 \mathrm{mM} \mathrm{MgCl} 2,0.5 \mathrm{U}$ DNA Taq polymerase (Thermo Fisher Scientific, USA), and

100 approximately 50-200 ng of template DNA. The PCR products were digested using restriction

101 endonuclease VspI (ER0911, Thermo Fisher Scientific, USA). The restriction reaction mixture

102 consisted of $10 \mu \mathrm{l}$ PCR product, $1.5 \mu 1$ restriction buffer, $3.25 \mu \mathrm{l} \mathrm{H}_{2} \mathrm{O}$, and $0.25 \mu \mathrm{l}(2.5 \mathrm{U})$ of

$103 V s p \mathrm{I}$, and was incubated for $3 \mathrm{~h}$ at $37^{\circ} \mathrm{C}$. DNA fragments after restriction were analyzed on 2.5

$104 \%$ agarose gel stained with ethidium bromide. In the case of $A$ allele fragments of 288 and 153

$105 \mathrm{bp}$ were obtained and in the case of G allele the PCR product remained uncut (442 bp). The

106 PCR/RFLP method was confirmed using Sanger sequencing of PCR products representing all

107 three genotypes. The fragments were treated with exonuclease I (ExoI) and alkaline phosphatase

108 (FastAP) (both Thermo Fisher Scientific, USA) for $15 \mathrm{~min}$ at $37^{\circ} \mathrm{C}$ prior to sequencing using

109 Big Dye v3.1 sequencing reaction (Thermo Fisher Scientific, USA) and the forward primer. The

110 fragments were purified using EDTA and ethanol, resuspended in formamide and sequenced on

111 ABI3100 gene analyzer (Applied Biosystems, USA).

112

113 Statistical analysis

114 A chi-square test was applied to test the genotype frequencies for deviations from Hardy-

115 Weinberg equilibrium. Forty-five G/G and $14 \mathrm{G} / \mathrm{A}$ animals were included in the analysis. The

116 rare homozygote $(\mathrm{A} / \mathrm{A})$ group size is small $(\mathrm{n}=2)$, therefore it was excluded from the analysis.

117 The analyzed data for 61 goats represents 863 recordings (14.6 per goat in average). The data

118 was not averaged by any of the variables included in the model (genotype, parity, consecutive

119 milk recording, and SCC). As SCC has a highly skewed distribution, the data was log-

120 transformed to obtain a normal distribution. Analysis of variance was performed with the general 
121 linear model (GLM) procedure of the SAS software (SAS Institute Inc. 2001, USA) according to 122 the following model:

$$
y_{i j k}=\mu+J_{i}+K_{j}+G_{k}+e_{i j k}
$$

124 where $y_{i j k}$ is log-transformed value of the SCC, $\mu$ is overall mean, $J_{i}$ is fixed effect of parity ( $\mathrm{i}=$ $1251-4), K_{j}$ is fixed effect of consecutive milk recording $(\mathrm{j}=1-7)$ (days in milk divided by 126 recording interval), $G_{k}$ is the effect of the genotype $(\mathrm{k}=G / A, G / G)$, and $e_{i j k}$ is residual error.

127 Statistical significance was declared at $\mathrm{p} \leq 0.05$.

128

\section{Results}

130 Genotyping of the 61 samples for the TLR2 $\mathrm{rs} 650082970 \mathrm{SNP}$ revealed $45 \mathrm{G} / G, 14 \mathrm{G} / \mathrm{A}$ and 2 $131 A / A$ genotypes, which corresponds to the allele frequencies of 0.85 and 0.15 for alleles $G$ and $A$, 132 respectively. The observed genotype frequencies do not deviate from Hardy-Weinberg 133 equilibrium according to the chi-square test ( $\mathrm{p}>0.05$ ). The $G / G$ and $G / A$ frequencies are similar 134 to the results of (Ruiz-Rodriguez et al., 2017), but in our sample collection we also found two 135 animals with the scarce $A / A$ genotype (due to low number we did not include them in the statistical analysis). Additionally, from publicly available database Genome Variation Map (http://bigd.big.ac.cn/gvm/) (Song et al., 2018) we extracted goat variation data for 211 goats of different populations (breeds) and estimated the average frequencies of the $G$ and $A$ alleles to approximately 0.8 and 0.2 , respectively. Allele frequencies seem to differ across breeds/populations with $A$ allele frequency ranging from 0 to 0.30 .

The validity of the PCR-RFLP genotyping method was confirmed by Sanger sequencing of PCR products for all the three different genotypes. The nucleotide sequences of PCR products matched the TLR2 target sequence (RefSeq NM_001285603.1) and are in accordance with the genotypes determined by PCR-RFLP method (Figure 1, A and B).

In the analysis of variance fixed effects of parity $(\mathrm{p}=0.0088)$, consecutive milk recording $(\mathrm{p}<$ $0.0001)$ and genotype $(\mathrm{p}=0.0007)$ were included. Generally, SCC was the lowest at the first milk recording and as expected increased with consecutive milk recordings (days in milk). Similarly, mean SCC was the lowest in the first parity and increased with consecutive parities. The statistical analysis showed significant effect of TLR2 genotype on the SCC score. SCCs in milk were lower in heterozygotes compared to $G / G$ homozygotes (Table 1). 


\section{Discussion}

154 Heterozygosity could be an advantage in pathogen recognition (Lenz et al., 2013), but in our case 155 there were not enough $A / A$ goats $(\mathrm{n}=2)$ to assess the effect of heterozygote advantage. However, despite there were only two $A / A$ animals it should be noted that their average SCC value was lower

157

158

159

160

161

162

163

164

165

166

167

168

169

170

171

172

173

174

175

176

177

178

179

180

181 than the average SCC values of the other two genotypes (not implying overdominance). From the available data it seems that the $A$ allele is the minor allele in goat populations and associated with lower SCC in goat milk, which makes the marker interesting for implementation to selection schemes for increased mastitis resistance. There is however some controversy whether selection to low SCC could eventually make animals more prone to mastitis, but the research shows that this is not the case (for a review see Rainard et al., 2018).

The analysed TLR2 polymorphism does not appear to have an obvious effect on the protein structure (Ruiz-Rodriguez et al., 2017), therefore it is possible that the analysed SNP is not the causative polymorphism associated with SCC in goat milk, but could be in linkage disequilibrium with the actual causative allele(s). Further studies are required to pile up the evidence for the SNP-SCC association in different breeds and to explain possible physiological effects of the polymorphism in relation to SCC and mastitis resistance.

\section{Conclusions}

In this study, we provide a validated PCR-RFLP based genotyping assay for the TLR2 SNP (rs650082970) and confirm the association of this SNP with milk SCC on a sample of the Slovenian Alpine breed does. Animals with the $A / G$ genotype had significantly $(\mathrm{p} \leq 0.05)$ lower SCC in milk compared to the $G / G$ genotype. The A allele seems to be the minor allele in goat populations and associated with lower milk SCC. Further studies are required to confirm the SNP-SCC association on a large number of animals in different breeds and to explain possible physiological effects of the polymorphism in relation to SCC and mastitis resistance or to identify the actual causative nucleotide(s), possibly linked with the analysed SNP.

\section{Acknowledgements}

The authors would like to thank Dr. Tine Pokorn and Dušan Birtič for technical assistance. 


\section{References}

183

184

185

186

187

188

189

190

191

192

193

194

195

196

197

198

199

200

201

202

203

204

205

206

207

208

209

210

211

212

213

214

215

216

217

218

219

220

221

222

223

224

225

226

227

Bai, J., J. Lin, W. Li, and M. Liu. 2012. Association of toll-like receptor 2 polymorphisms with somatic cell score in Xinjiang Brown cattle. Anim Sci J 83(1):23-30. doi: 10.1111/j.17400929.2011.00909.x

Bergonier, D., R. de Cremoux, R. Rupp, G. Lagriffoul, and X. Berthelot. 2003. Mastitis of dairy small ruminants. Vet Res 34(5):689-716. doi: 10.1051/vetres:2003030

Ezzat Alnakip, M., M. Quintela-Baluja, K. Böhme, I. Fernández-No, S. Caamaño-Antelo, P. Calo-Mata, and J. Barros-Velázquez. 2014. The Immunology of Mammary Gland of Dairy Ruminants between Healthy and Inflammatory Conditions. J Vet Med 2014doi: $10.1155 / 2014 / 659801$

Goldammer, T., H. Zerbe, A. Molenaar, H. J. Schuberth, R. M. Brunner, S. R. Kata, and H. M. Seyfert. 2004. Mastitis increases mammary mRNA abundance of beta-defensin 5, tolllike-receptor 2 (TLR2), and TLR4 but not TLR9 in cattle. Clin Diagn Lab Immunol 11(1):174-185.

Gunther, J., K. Esch, N. Poschadel, W. Petzl, H. Zerbe, S. Mitterhuemer, H. Blum, and H. M. Seyfert. 2011. Comparative kinetics of Escherichia coli- and Staphylococcus aureusspecific activation of key immune pathways in mammary epithelial cells demonstrates that $S$. aureus elicits a delayed response dominated by interleukin-6 (IL-6) but not by $I L$ $1 A$ or tumor necrosis factor alpha. Infect Immun 79(2):695-707. doi: 10.1128/iai.0107110

Kawai, T., and S. Akira. 2011. Toll-like receptors and their crosstalk with other innate receptors in infection and immunity. Immunity 34(5):637-650. doi: 10.1016/j.immuni.2011.05.006

Leitner, G., N. Silanikove, and U. Merin. 2008. Estimate of milk and curd yield loss of sheep and goats with intrammamary infection and its relation to somatic cell count. Small Ruminant Research 74(1-3):221-225. doi: 10.1016/j.smallrumres.2007.02.009

Lenz, T. L., B. Mueller, F. Trillmich, and J. B. Wolf. 2013. Divergent allele advantage at MHCDRB through direct and maternal genotypic effects and its consequences for allele pool composition and mating. Proc Biol Sci 280(1762):20130714. doi: 10.1098/rspb.2013.0714

Mitterhuemer, S., W. Petzl, S. Krebs, D. Mehne, A. Klanner, E. Wolf, H. Zerbe, and H. Blum. 2010. Escherichia coli infection induces distinct local and systemic transcriptome responses in the mammary gland. BMC Genomics 11:138. doi: 10.1186/1471-2164-11138

Mogensen, T. H. 2009. Pathogen Recognition and Inflammatory Signaling in Innate Immune Defenses. Clin Microbiol Rev 22(2):240-273.

Paape, M. J., and A. V. Capuco. 1997. Cellular defense mechanisms in the udder and lactation of goats. J Anim Sci 75(2):556-565.

Paape, M. J., G. R. Wiggans, D. D. Bannerman, D. L. Thomas, A. H. Sanders, A. Contreras, P. Moroni, and R. H. Miller. 2007. Monitoring goat and sheep milk somatic cell counts. Small Ruminant Research 68(1):114-125. doi: https://doi.org/10.1016/j.smallrumres.2006.09.014

Rainard, P., Foucras, G., Boichard, D., Rupp, R. 2018. Invited review: Low milk somatic cell count and susceptibility to mastitis. J Dairy Sci 101(8): 6703-6714.

Raynal-Ljutovac, K., A. Pirisi, R. d. Crémoux, C. Gonzalo. Somatic cells of goat and sheep milk: Analytical, sanitary, productive and technological aspects. Small Ruminant Research 68(1):126-144. doi: 10.1016/j.smallrumres.2006.09.012

Peer) reviewing PDF | (2019:03:35824:1:1:NEW 17 May 2019) 
Ruiz-Rodriguez, C. T., J. R. Brandt, R. Oliverio, Y. Ishida, N. Guedj, E. F. Garrett, G. Kahila Bar-Gal, N. Nikolaidis, F. C. Cardoso, and A. L. Roca. 2017. Polymorphisms of the TollLike Receptor 2 of Goats (Capra hircus) may be Associated with Somatic Cell Count in Milk. Anim Biotechnol 28(2):112-119. doi: 10.1080/10495398.2016.1232267

Schroder, N. W., S. Morath, C. Alexander, L. Hamann, T. Hartung, U. Zahringer, U. B. Gobel, J. R. Weber, and R. R. Schumann. 2003. Lipoteichoic acid (LTA) of Streptococcus pneumoniae and Staphylococcus aureus activates immune cells via Toll-like receptor (TLR)-2, lipopolysaccharide-binding protein (LBP), and CD14, whereas TLR-4 and MD2 are not involved. J Biol Chem 278(18):15587-15594. doi: 10.1074/jbc.M212829200 Silanikove, N., U. Merin, and G. Leitner. 2014. On effects of subclinical mastitis and stage of lactation on milk quality in goats. Small Ruminant Research 122(1-3):76-82. doi: 10.1016/j.smallrumres.2014.07.018

Song, S., D. Tian, C. Li, B. Tang, L. Dong, J. Xiao, Y. Bao, W. Zhao, H. He, and Z. Zhang. 2018. Genome Variation Map: a data repository of genome variations in BIG Data Center. Nucleic Acids Res 46(D1):D944-d949. doi: 10.1093/nar/gkx986

Stelwagen, K., E. Carpenter, B. Haigh, A. Hodgkinson, and T. T. Wheeler. 2009. Immune components of bovine colostrum and milk. J Anim Sci 87(13 Suppl):3-9. doi: $10.2527 /$ jas.2008-1377

Wilson, D. J., K. N. Stewart, and P. M. Sears. 1995. Effects of stage of lactation, production, parity and season on somatic cell counts in infected and uninfected dairy goats. Small Ruminant Research 16(2):165-169. doi: https://doi.org/10.1016/0921-4488(95)00622-R 
Figure 1

Genotypes of the TLR2 locus for the SNP (rs650082970).

(A) Gel electrophoresis of the PCR-RFLP assay for genotyping the rs650082970 SNP.

Genotypes G/G, G/A and A/A are presented. (B) Sanger sequences of the PCR products for the three genotypes. Two peaks are clearly visible in the case of heterozygote (GA) animal. 
A)

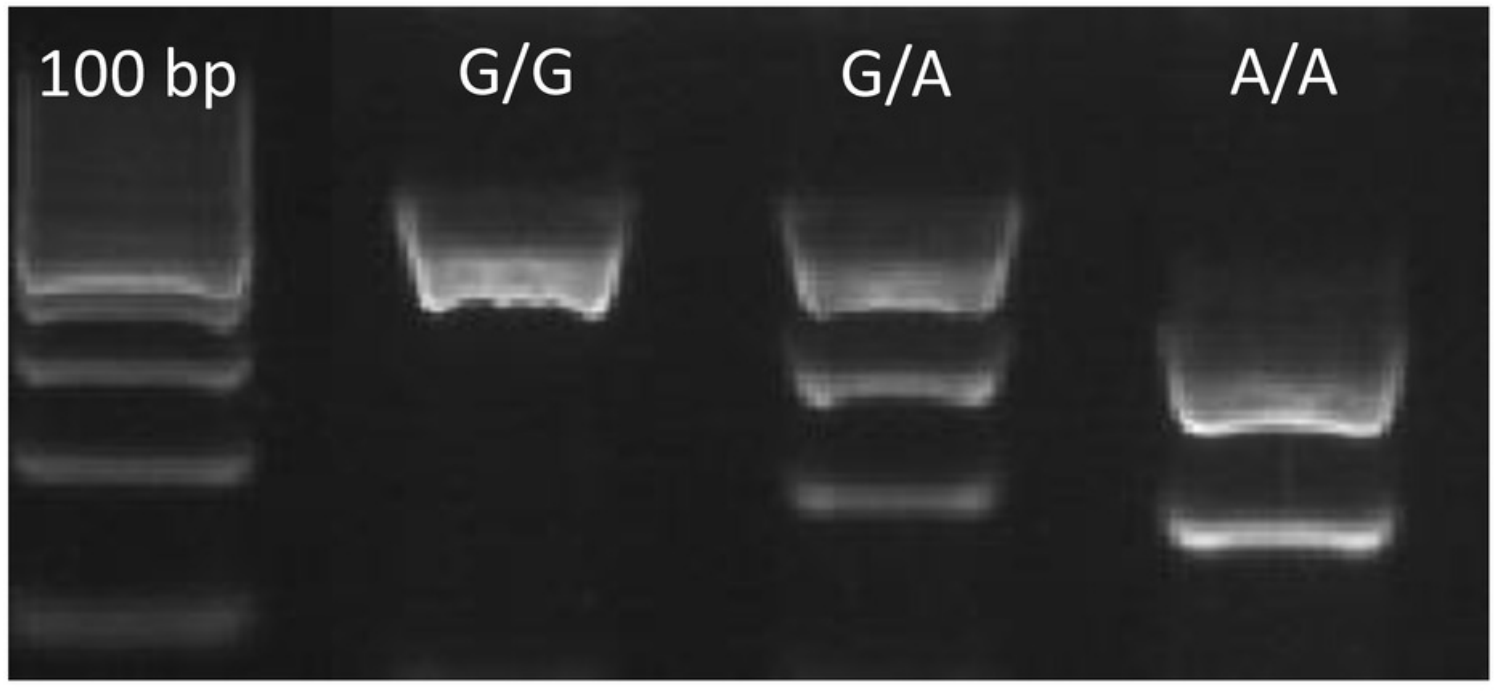

B)

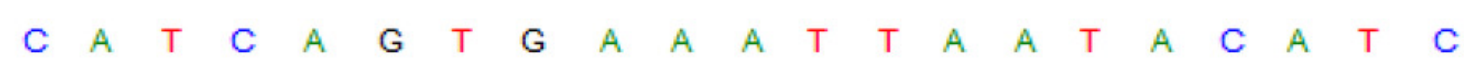

\section{G/A}

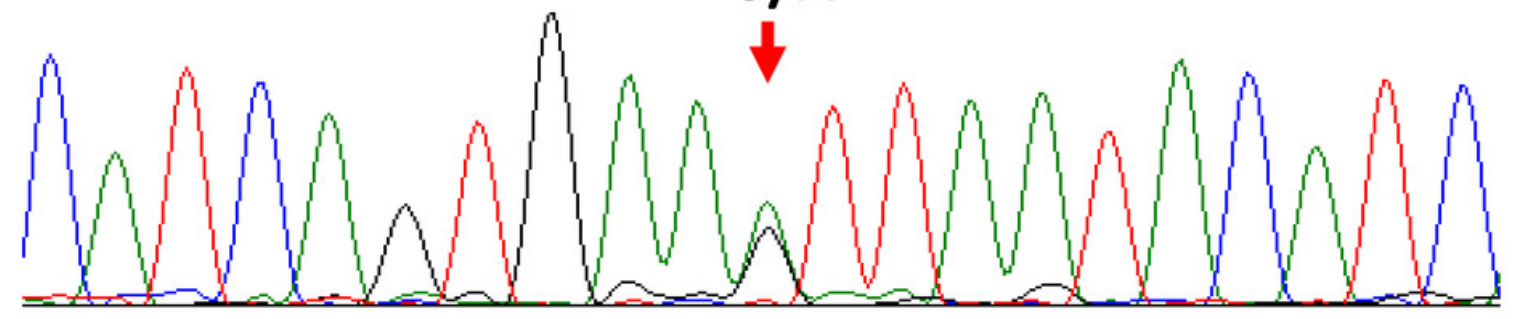

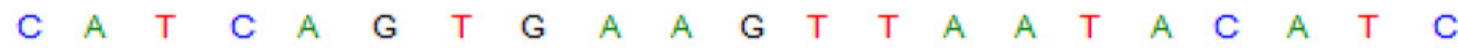

G/G

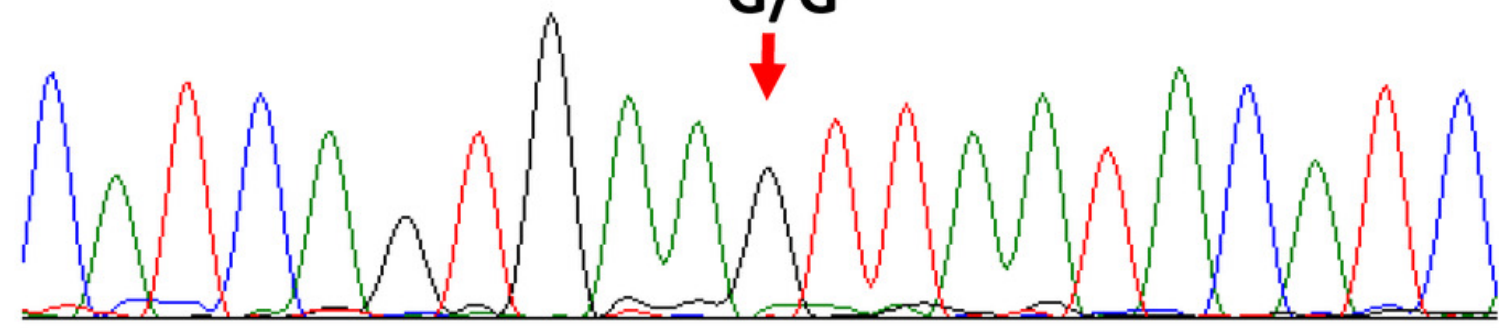

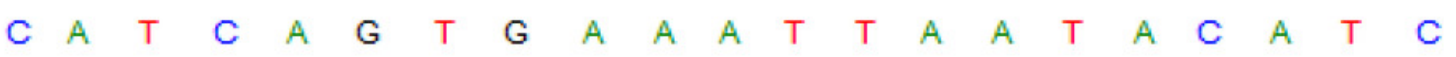

A/A

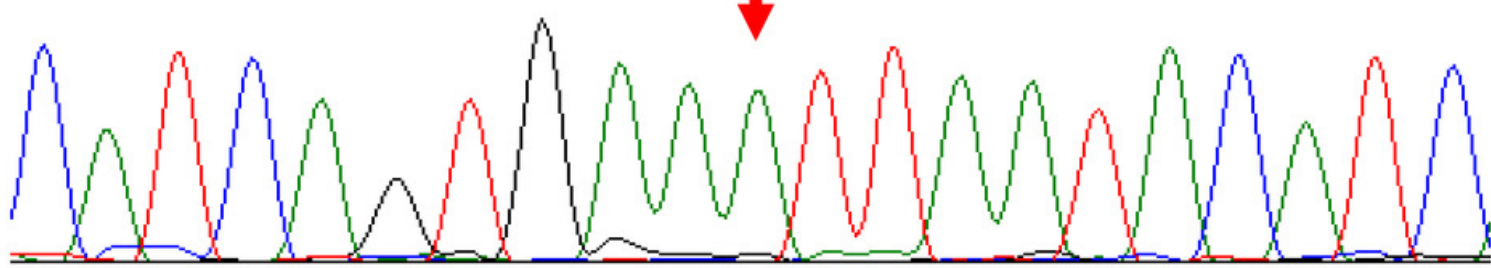




\section{Table $\mathbf{1}$ (on next page)}

SCC $\left(x 10^{3}\right)$ by the genotype of the TLR2 polymorphism (rs650082970).

* LSM - least squares means; SE - standard error; ${ }^{c, d}$ superscript letters denote statistically significant differences among groups of animals carrying different genotypes. 
1 Table 1 SCC $\left(x 10^{3}\right)$ by the genotype of the TLR2 polymorphism (rs650082970).

\begin{tabular}{lccccc}
\hline Effect & Goats & Records & \multicolumn{3}{c}{ SCC $\left(\times 10^{3}\right)$} \\
\hline Genotype & & & Mean & Log ${ }^{*}$ LSM & ${ }^{*}$ SE \\
\hline A/A & 2 & 35 & 577.11 & $/$ & $/$ \\
G/A & 14 & 208 & 1055.38 & $6.58^{\mathrm{c}}$ & 0.16 \\
G/G & 45 & 620 & 1475.66 & $6.89^{\mathrm{d}}$ & 0.15
\end{tabular}

2 * LSM - least squares means; SE - standard error; c,d superscript letters denote statistically significant 3 differences among groups of animals carrying different genotypes. 